\title{
FASCIOCUTANEOUS BLOOD SUPPLY IN BELOW-KNEE AMPUTATION
}

\author{
M. D. HUMZAH, P. M. GILBERT \\ From St John's Hospital, Livingston, Scotland
}

\begin{abstract}
Skin cover after below-knee amputation has been extensively discussed. We describe the flaps which are commonly used and discuss their vascular basis in the context of the current knowledge of the fasciocutaneous system. An understanding of this vascular system will enable surgeons to plan and shape flaps for surgical exposure and coverage.
\end{abstract}

J Bone Joint Surg [Br] 1997;79-B:441-3.

Received 10 July 1996; Accepted after revision 30 September 1996

Amputation of the lower limb is a recognised procedure in the surgical management of patients with vascular problems. To allow the patient to maintain an active, mobile life, most surgeons favour below-knee amputation when possible. ${ }^{1}$ Unfortunately, with some procedures, failure of wound healing is a common complication. ${ }^{2}$ Many different flaps have been designed to reconstruct the lower limb after amputation but the basis for their survival has not always been addressed. An understanding of the anatomical basis and vascular anatomy of the underlying fascia is important in understanding this. The flaps used in the reconstruction of the lower limb below the knee are discussed with the current knowledge of the cutaneous blood supply.

Below-knee amputation. Below-knee amputation using a long posterior flap was described by Kendrick in $1956^{3}$ and subsequently popularised by Burgess using a myoplasty and early walking. ${ }^{4}$ Although this technique is still used in many units myodesis is not recommended in the presence of poor vascular function because of problems with wound healing due to the poor local blood supply. ${ }^{5,6}$ The long posterior flap consists of muscle, deep fascia, subcutaneous tissue and overlying skin which is then turned over the tibial stump. Folding of this thick flap anteriorly results in

M. D. Humzah, FRCS, Specialist Registrar in Plastic Surgery

P. M. Gilbert, FRCS, Consultant Plastic Surgeon

St John's Hospital at Howden, Howden Road West, Livingston EH54 6PP, UK.

Correspondence should be sent to Mr M. D. Humzah.

(C)1997 British Editorial Society of Bone and Joint Surgery 0301-620X/97/37078\$2.00 shearing of the different layers within it, principally at the fat-fascia interface, which is the weakest point. Hence the vascularity of the overlying skin is compromised and wound breakdown may occur.

The skew-flap, described by Robinson et $\mathrm{al}^{7}$, raises anteromedial and posterolateral flaps which include the fat and deep fascia. They are separate from the gastrocnemius/ soleus mass which is trimmed and used to cover the tibial stump. The skin/fascia flaps enclose the posterior muscle flap and are independent of it. These authors did not discuss the success of this technique in relation to the blood supply (see below).

The technique described by Tracey ${ }^{8}$ and refined by $\mathrm{Au},{ }^{9}$ utilises equal-sized sagittal flaps, which include fascia and muscle, on the medial and lateral sides of the calf. These flaps have a larger breadth:length ratio than the conventional posterior flap which is said to account for their superiority.

Medially-based flaps have also been employed ${ }^{10}$ with the base situated between $30^{\circ}$ and $70^{\circ}$ medial to the posterior flap. The gastrocnemius, deep fascia and skin constitute the major components of this flap and the concept is based on the observed medial-to-lateral gradient of blood flow in the skin below the knee.

The local blood supply is an important factor in healing and the integrity of the skin/fascia interface is essential in closing the defect, independent of the underlying muscle. Vascularity of the flap. In 1981 Ponten described the clinical use of fasciocutaneous flaps in the lower limb. ${ }^{11} \mathrm{He}$ demonstrated flaps with a length:breadth ratio of at least 2.5:1. Before this it had been generally accepted that flaps with a length:breadth ratio greater than $1: 1$ had little chance of survival in the leg. These represented skin flaps that were elevated with the underlying deep fascia still attached. $^{12}$

The vascular anatomy of the skin and deep fascia has been extensively studied from the early work of Wladimir Tomsa of $\mathrm{Kiev}^{13}$ on the blood vessels of the skin, to the most recent descriptions of fascial vascularity by Batchelor and Moss. ${ }^{14}$ Timmons reviewed many largely forgotten papers on this subject in 1985 . $^{15}$ It is now understood that a series of blood vessels pass towards the surface of the body along the fascial septa between muscle groups. These septal perforators communicate with vessels of the deep fascia to form a plexus from which branches supply the 


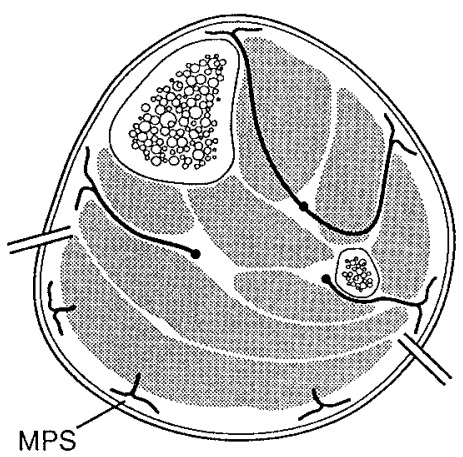

(a) Posterior Flap

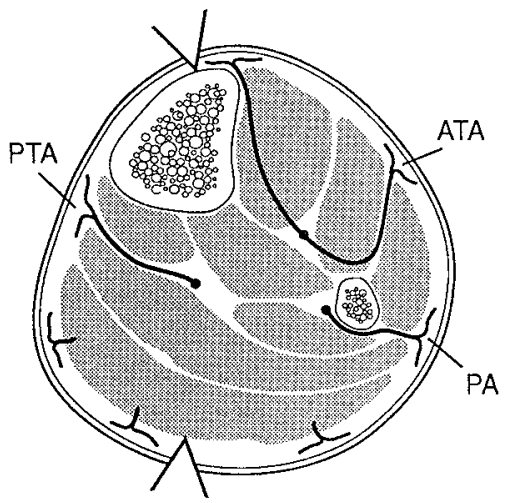

(c) Sagittal Flap

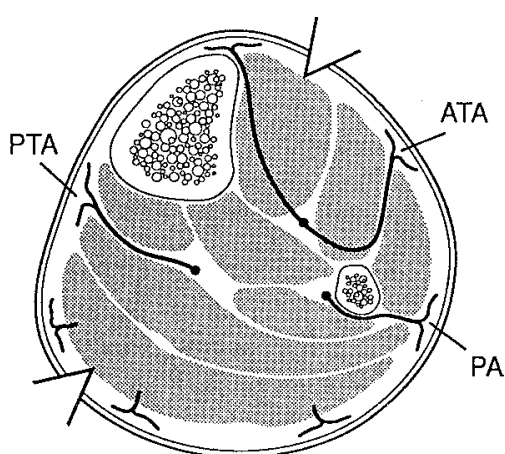

(b) Skew Flap

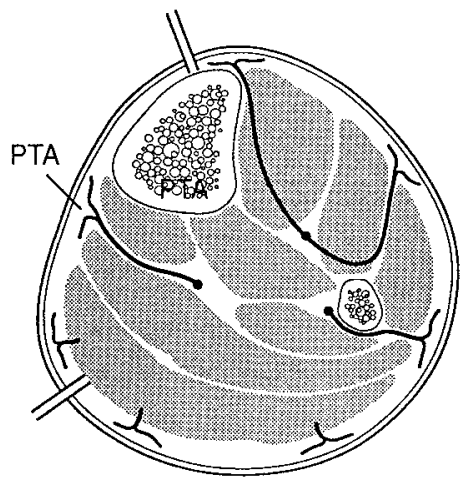

(d) Medial Flap

Fig. 1

Diagrams showing position of fasciocutaneous perforators to skin flaps. (MPS = musculocutaneous perforators from sural artery, PTA $=$ posterior tibial artery, ATA $=$ anterior tibial artery, PA = peroneal artery, (adapted from The arterial anatomy of skin flaps. G. C. Cormack \& B. G. H. Lamberty, Churchill Livingstone)).

overlying subcutaneous tissue and skin. ${ }^{16}$ The plexus itself has a complex arrangement of suprafascial, subfascial and intrafascial vessels. ${ }^{17}$ There are also thoroughfare vessels within the capillary bed of fascial flaps which enable arteriovenous shunting to occur. ${ }^{18}$ The anatomical position and distribution of the fasciocutaneous perforators have been described in detail, ${ }^{19,20}$ showing that, in the lower limb, perforating blood vessels from the anterior tibial, posterior tibial, saphenous, sural and peroneal arteries supply the deep fascia and overlying skin. Clinically, as long as the skin and subcutaneous tissues are not stripped off the underlying fascia they will receive an axial-pattern blood supply.

These findings can be applied to consideration of the viability of the various flaps used for covering the tibial stump as shown in Figure 1 which is modified from Cormack and Lamberty. ${ }^{20}$ A long posterior flap may survive in part as a fasciocutaneous flap supplied by musculocutaneous perforators of the sural artery emerging through the gastrocnemius (Fig. 1a). ${ }^{21}$ The distal portion, however, which is used to obtain skin closure will usually have no underlying fascia in an area where the skin flap has been turned to almost $180^{\circ}$ to cover the stump. In turning the flap, the different layers will be subjected to shearing forces, particularly at the fat-fascia interface, similar to a classical degloving injury, further compromising the vascularity. The combination of a long flap, turned forwards, without an adequate blood supply especially to its distal portion, in the presence of peripheral vascular disease will result in poor healing.

The skew-flap raises anteromedial and posterolateral flaps of equal length with the deep fascia still attached. Reference to the described positions of fasciocutaneous perforators in the lower limb ${ }^{20}$ shows that the anteromedial flap contains perforators from the posterior tibial and saphenous arteries, and that the posterolateral flap contains perforators from the anterior tibial, sural and peroneal arteries. Each fasciocutaneous unit is well vascularised and can be moved independently from the underlying muscle which has its own blood supply (Fig. 1b). The clinical reliability of the skew flap has been confirmed by Harrison et al. $^{2}$

The sagittal flap ${ }^{8,9}$ is reported to yield better results because of the cross-sectional anatomy of the calf. Since 
the sagittal diameter is greater than the coronal diameter, sagittal flaps have a favourable breadth:length ratio. On examination of the anatomy, ${ }^{19}$ however, it is seen that the medial flap is supplied mostly by the saphenous artery and fasciocutaneous perforators from the posterior tibial artery. The lateral flap is supplied for most of its length by fasciocutaneous perforators from the anterior tibial artery and there may also be a contribution from perforators arising from the peroneal artery (Fig. 1c).

The medial flap proposed by Jain et $\mathrm{al}^{10}$ is based similarly on studies which demonstrate a significant medial to lateral gradient of blood flow in the skin below the knee. ${ }^{6}$ This occurs because the medial side of the lower limb is supplied by the saphenous artery and perforators from the posterior tibial artery (Fig. 1d). ${ }^{20}$ This dual source of supply to the medial side of the leg explains both the observed gradient of blood flow and the success in wound healing. 10

\section{CONCLUSIONS}

A knowledge of the blood supply to the skin is necessary in order that it may be preserved during operation to encourage wound healing. An understanding of the blood supply to the muscle component and to the fasciocutaneous element gives the surgeon an anatomical basis for using each component independently of the other. This allows alteration of the position and shape of skin flaps in situations in which classical approaches cannot be utilised, such as previous scarring or trauma. Application of the principles of elevating fasciocutaneous flaps will enable surgeons to plan incisions and exposures so that maximum viability of the skin is maintained.

Our thanks to Lesley Skeates, Medical Illustrator, at The Royal Hospital for Sick Children in Edinburgh for the production of the figures in this manuscript.

No benefits in any form have been received or will be received from a commercial party related directly or indirectly to the subject of this article.

\section{REFERENCES}

1. Pederson HE. The problem of the geriatric amputee. Artific Limbs 1968;12:1-3.

2. Harrison JD, Southworth S, Callum KG. Experience with the 'skew flap' below-knee amputation. Br J Surg 1987;74:930-1.

3. Kendrick RR. Below-knee amputation in arteriosclerotic gangrene. Br J Surg 1956;44:13-7.

4. Burgess EM, Romano RL, Zettl JH. The management of lower extremity amputations. 11 TR: 10-6. Prosthetic and Senory Aids Service. US Veteran Administration, 1969.

5. Fulford GA. Symposium on amputation surgery. Queen Mary's Hospital, Roehampton, 1967.

6. McCollum PT, Spence VA, Walker WF, Murdoch G. A rationale for skew flaps in below-knee amputation surgery. Prosthet Orthot Int 1985;9:95-9.

7. Robinson KP, Hoile R, Coddington T. Skew flap myoplastic belowknee amputation: a preliminary report. Br J Surg 1982;69:554-7.

8. Tracey GD. Below-knee amputation for ischaemic gangrene. Pacif Med Surg 1966;74:177-84.

9. Au KK. Sagittal flaps in below-knee amputations in Chinese patients. J Bone Joint Surg [Br] 1989;71-B:597-8.

10. Jain AS, Stewart CP, Turner MS. Transtibial amputation using a medially based flap. J R Coll Surg Edinb 1995;40:263-5.

11. Pontén B. The fasciocutaneous flap: its use in soft tissue defects of the lower leg. Br J Plast Surg 1981;34:215-20.

12. Haertsch $\mathbf{P}$. The surgical plane in the leg. $\mathrm{Br} J$ Plast Surg 1981;34:464-9.

13. Tomsa W. Beitrage zur Anatomie und Physiologie der menschlichen Haut. Archiv Dermatol Syphilis 1873;5:1.

14. Batchelor JS, Moss AL. The relationship between fasciocutaneous perforators and their fascial branches: an anatomical study in human cadaver lower legs. Plast Reconstr Surg 1995;95:629-33.

15. Timmons MJ. Landmarks in the anatomical study of the blood supply of the skin. Br J Plast Surg 1985;38:197-207.

16. Schafer K. Studies on angioarchitecture of the fascia (lower extremity). Z Anat Entwicklungsgesch 1972;139:21-54.

17. Lang $\mathbf{J}$. On the texture and vascularisation of fascia. Acta Anatl 1962;48:61-94.

18. Batchelor JS, Rahim A, McGuinness A. The anatomic basis for arteriovenous shunting in human lower leg fascial flaps. Plast Reconstr Surg 1995;95:233-9. Discussion 240-2.

19. Haertsch PA. The blood supply to the skin of the leg: a postmortem investigation. Br J Plast Surg 1981;34:470-7.

20. Cormack GC, Lamberty BGH. The arterial anatomy of skin flaps. Edinburgh, etc: Churchill Livingston, 1995.

21. Gray DW, Ng RL. Anatomical aspects of the blood supply to the skin of the posterior calf: technique of below-knee amputation. Br J Surg 1990;77:662-4. 